\title{
Detection of Meta-Stable Peaks by Mattauch-Herzog Mass Spectrometer*
}

\author{
S. SASAKI,** E. YAMAUCHI,***, Y. ITAGAKI,*** \\ M. NAITO*** and E. WATANABE***
}

(Received December, 28, 1967)

\begin{abstract}
Daughter ions from metastable ions were detected on photo plate in Mattauch-Herzog geometry by the gradual shift of accelerating voltage. By this technique the most possible fragmentations of 3, 4-epoxymenthane, $l$-menthone and piperitol were presented.
\end{abstract}

The observation of meta-stable ions is very important in the study of fragmentation of mass spectra. In Mattauch-Herzog geometry, however, a daughter ion from a meta-stable ion produced between the object slit and the electrostatic field has insufficient kinetic energy and so cannot pass through the electrostatic field ${ }^{1)}$; therefore none of these daughter ions can be detected on the photo plate.

In the case of a decomposition of $\mathrm{m}_{1}{ }^{+} \rightarrow \mathrm{m}_{2}{ }^{+}+\left(\mathrm{m}_{1}-\mathrm{m}_{2}\right)$ which shows meta-stable ion formation, the energy of the ion $\mathrm{m}_{1}{ }^{+}$, at the accelerating voltage $\mathrm{V}$, is distributed as follows:

$$
\mathrm{eV} \rightarrow \frac{\mathrm{m}_{2}}{\mathrm{~m}_{1}} \mathrm{eV}+\frac{\mathrm{m}_{1}-\mathrm{m}_{2}}{\mathrm{~m}_{1}} \mathrm{eV}
$$

The ion $\mathrm{m}_{2}{ }^{+}$cannot pass the electrostatic field because it has an energy of only $\mathrm{m}_{2} / \mathrm{m}_{1} \cdot \mathrm{eV}$. So, if the accelerating voltage is increased to $\mathrm{V}^{\prime}=\mathrm{m}_{1} / \mathrm{m}_{2} \cdot \mathrm{V}$, the energy of ion $\mathrm{m}_{2}{ }^{+}$produced between the object slit and the electrostatic field will be as follows:

$$
\frac{\mathrm{m}_{1}}{\mathrm{~m}_{2}} \mathrm{eV}=\frac{\mathrm{m}_{2}}{\mathrm{~m}_{1}} \mathrm{e}\left(\left(\frac{\mathrm{m}_{1}}{\mathrm{~m}_{2}}\right) \mathrm{V}\right)=\mathrm{eV}
$$

This energy of $\mathrm{eV}$ for the ion $\mathrm{m}_{2}{ }^{+}$(produced between the object slit and the electrostatic field), in the case of accelerating voltage $\mathrm{V}^{\prime}$, is the same as that of $\mathrm{m}_{1}{ }^{+}$at an accelerating voltage $\mathrm{V}$. In other words the ion $\mathrm{m}_{2}{ }^{+}$(produced between the object slit and the electrostatic field) can be detected at the same place as the ion $\mathrm{m}_{2}{ }^{+}$(produced in the ionisation chamber just as $\mathrm{m}_{1}{ }^{+}$, at the accelersting voltage of $\mathrm{V}$ ) by varying the accelerating voltage from $\mathrm{V}$ to $\mathrm{V}^{\prime}$. (Fig. 1)

Fig. 2 shows the actual example of noteworthy daughter ions from meta-stable ions which have besn detected in 3,4-epoxymenthane ${ }^{2,3)}$ by this method. The observed and calculated daughter ions from meta-stable ions and possible break-down reactions deduced from them are shown in Table I.

* A part of this paper will be appeared on the Anal. Chem.

** Department of Chemistry, Miyagi University of Education, Sendai, Japan

*** Japan Electron Optics Laboratory Co., Ltd., Akishima, Tokyo, Japan 


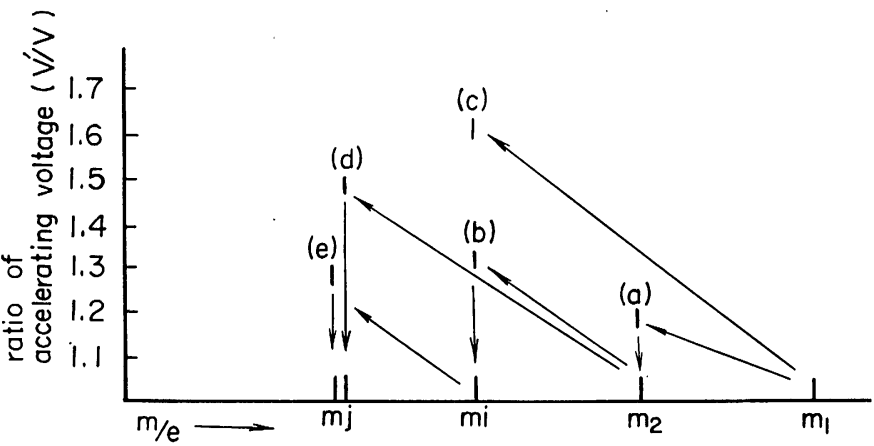

Fig. 1. Daughter ions from meta-stable ions datected on photo plate by the shift of accelerating voltage $\left(\mathrm{V} \rightarrow \mathrm{V}^{\prime}\right)$

(a) a daughter ion from meta-stable ion presenting the

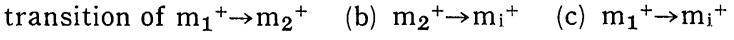
(d) $\mathrm{m}_{2}{ }^{+} \rightarrow \mathrm{m}_{\mathrm{j}}^{+}$
(e) $\mathrm{mi}_{\mathrm{i}}^{+} \rightarrow \mathrm{m}_{\mathrm{j}}^{+}$

Furthermore the exact mass measurements for several prominent peaks of this compound are carrid out, and the values thereof are shown in Table II. These values indicate that the ions at $\mathrm{m} / \mathrm{e} 71$ and 83 in 3, 4-epoxymenthane are contributed by two different ions: the former $\mathrm{C}_{5} \mathrm{H}_{11}{ }^{+}$ and $\mathrm{C}_{4} \mathrm{H}_{7} \mathrm{O}^{+}$, and the latter $\mathrm{C}_{6} \mathrm{H}_{11}{ }^{+}$and $\mathrm{C}_{5} \mathrm{H}_{7} \mathrm{O}^{+}$, respectively.

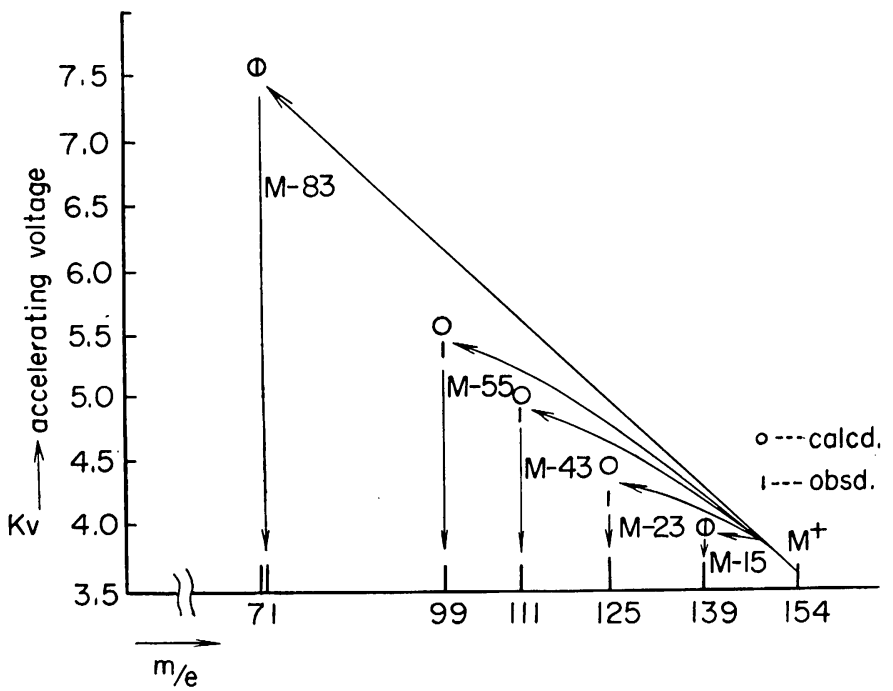

Fig. 2. Daughter ions from meta-stable ions of 3,4-epoxymenthane detected on photo plate by the shift of accelerating voltage $(3.5 \mathrm{KV} \rightarrow 7.6 \mathrm{KV})$

Table I. Possible break-down reactions of 3, 4-epoxymenthane deduced from the daughter ions from meta-stable ions(See Fig. 2)

\begin{tabular}{ccccc}
\hline \multicolumn{2}{c}{ obsd. } & \multicolumn{2}{c}{ calcd. } & transition \\
\hline $\mathrm{V}^{\prime} / \mathrm{V}$ & $\mathrm{V}^{\prime}$ & $\mathrm{V}^{\prime} / \mathrm{V}$ & $\mathrm{V}^{\prime}$ & \\
1.11 & 3.88 & 1.11 & 3.88 & $154^{+} \rightarrow 139^{+}+15$ \\
& & \multicolumn{2}{c}{$-180-$} &
\end{tabular}


Vol. 15, No. 3-4, December 1967

Sasaki et. al.

$1.26 \quad 4.41$

1. $40 \quad 4.90$

1.23

1. 39

1.56

5.53

7.59

2. 17

a-Stable Peaks

1.58

4. 31

$154^{+} \rightarrow 125^{+}+29$

4.86

$154^{+} \rightarrow 111^{+}+43$

2.17

5.46

$154^{+} \rightarrow 99^{+}+55$

7.59

$154^{+} \rightarrow 71^{+}+83$

Table II. Exact mass measurements of 3,4-epoxymenthane

\begin{tabular}{llll}
\hline & obsd. & calcd. & \multicolumn{1}{c}{ composition } \\
\hline m/e 99 & .081 & .084 & $\mathrm{C}_{6} \mathrm{H}_{11} \mathrm{O}$ \\
m/e 83 & .086 & .085 & $\mathrm{C}_{6} \mathrm{H}_{11}$ \\
& .050 & .047 & $\mathrm{C}_{5} \mathrm{H}_{7} \mathrm{O}$ \\
$\mathrm{m} / \mathrm{e} 71$ & .086 & .083 & $\mathrm{C}_{5} \mathrm{H}_{11}$ \\
& .050 & .048 & $\mathrm{C}_{4} \mathrm{H}_{7} \mathrm{O}$ \\
m/e 43 & .055 & .055 & $\mathrm{C}_{3} \mathrm{H}_{7}$ \\
\hline
\end{tabular}

Mass values are based on $\mathrm{C}^{12}=12.000$

Thus the combination of the detection of daughter ions from meta-stable ions by abovementioned technique and the ordinary exact mass measurements suggests the following fragmentation process for 3, 4-epoxymenthane. (Fig. 3)
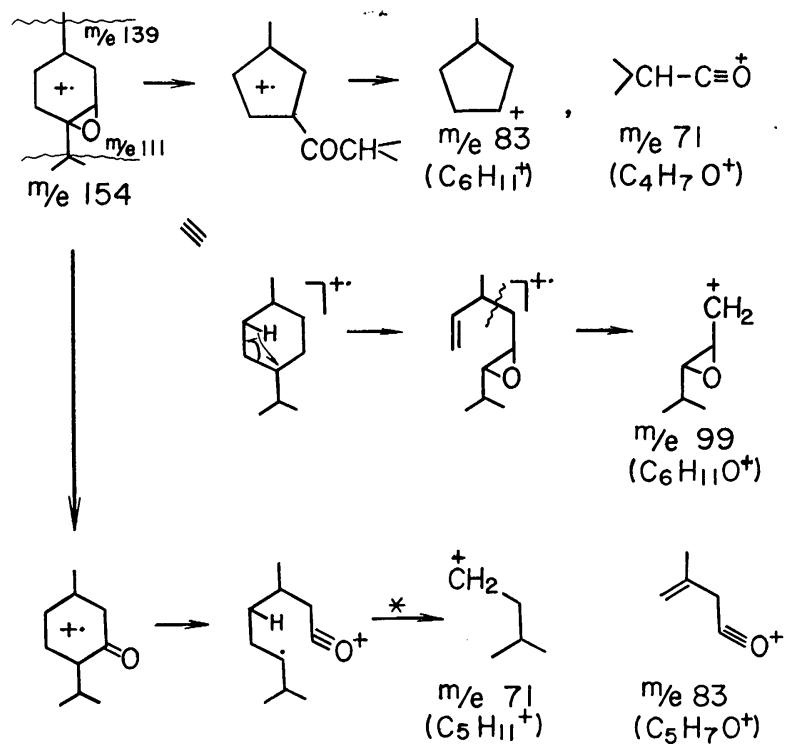

The transition marked with $*$ is deduced only by the exact mass measurements of the ions $\mathrm{C}_{5} \mathrm{H}_{11}{ }^{+}$and $\mathrm{C}_{5} \mathrm{H}_{7} \mathrm{O}^{+}$.

Fig. 3. Fragmention of 3,4-epoxymenthane established by the detection of daughter ions from meta-stable ions and the exact mass measurements 
Furthermore, the fragmentation pathways ara suggasted as follows for $l$-menthone and piperitol by the technique to detect daughter ions from meta-stable ions. (Fig. 4 and 5)

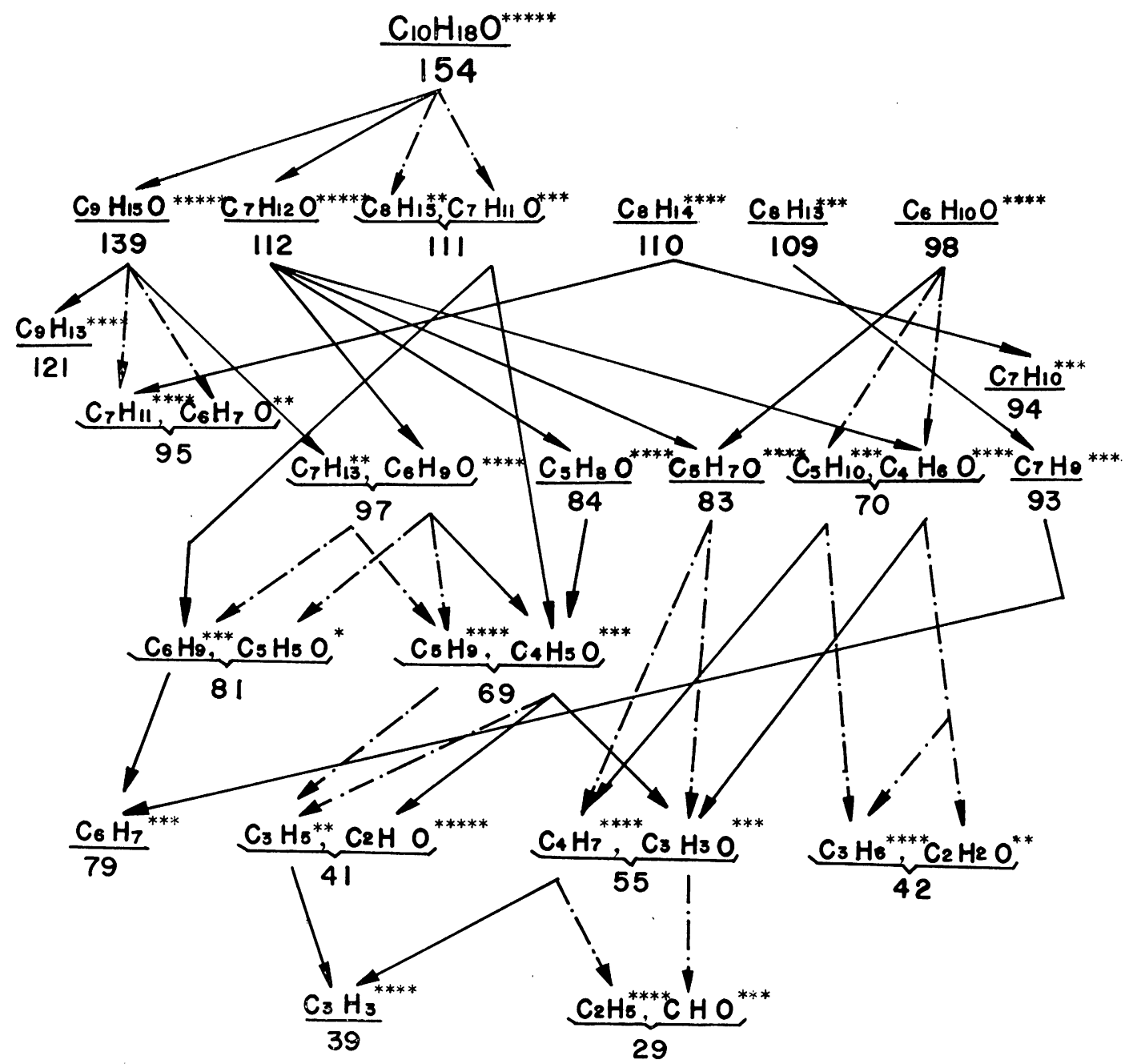

Fig. 4. Fragmentation process of $l$-menthone

$\longrightarrow$ Transition in which the meta-stable ion has been observed.

$-\rightarrow$ Another transition is also conceivable because the daughter ion has not been displayed as a doublet, despite the fact that the meta-stable ion has been observed.

*** Number of asterisk corresponds to intensity of ions.

\section{Experiment}

The mass spectra were measured with JMS-OISG mass spectrometer with ionizing voltage $75 \mathrm{eV}$, ionizing current $150 \mu \mathrm{A}$, ion accelerating voltage $3.5 \mathrm{kV} \rightarrow 8 \mathrm{kV}$, exposed time 1 min., and the temperature of ion soure $130 \rightarrow 140^{\circ} \mathrm{C}$. 


\section{Vol. 15, No. 3-4, December $1967 \quad$ Detection of Meta-Stable Peaks}

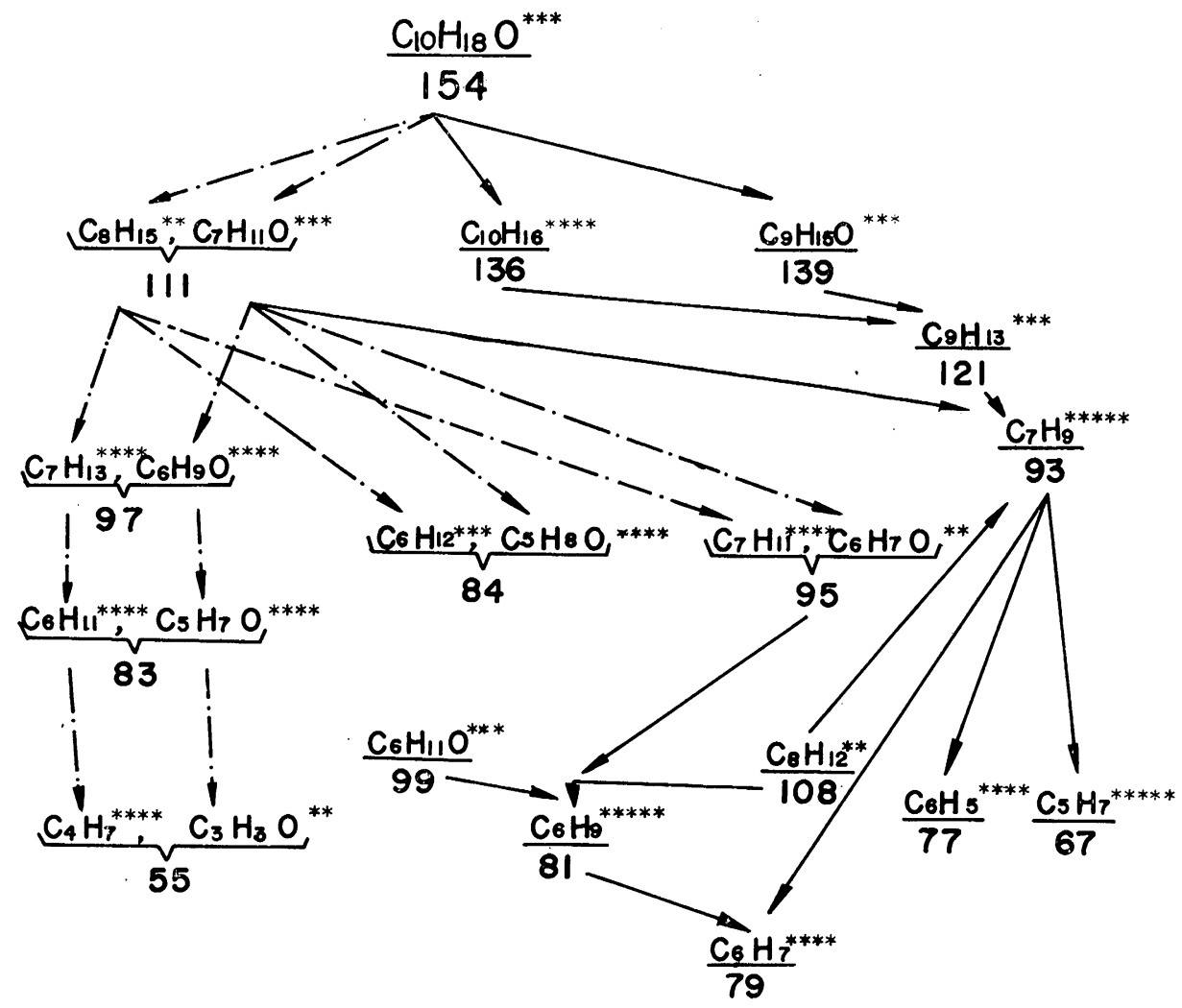

Fig. 5. Fragmentation process of piperitol

$\longrightarrow$ Transition in which the meta-stable ion has been observed.

$\rightarrow$ Another transition is also conceivable because the daughter ion has not been displayed as a doublet, despite the fact that the meta-stable ion has been observed.

*** Number of asterisk corresponds to intensity of ions.

3, 4-Epoxymenthane was synthesized by the epoxidation of 3-menthene. ${ }^{3)} \quad l$-Menthone and piperitol are commercially available.

\section{Literatures}

1) M. Berber and R. M. Elliot, 12th Ann. Meeting. ASTM E-14, Montreal (1964).

2) Y. Itagaki, T. Kurokawa, H. Moriyama, S. Sasaki and Y. Watanabe, Chemistry and Industry, 1965, 1654.

3) S. Sasaki, Y. Itagaki, H. Moriyama, K. Nakanishi, E. Watanabe and T. Aoyama, Tetrahedron Letters, No. 6, 623 (1966). 